\title{
The creation and evolution of porosity during mineral-fluid interactions: a combined USANS/SANS, microscopy, and synchrotron PXRD study
}

MUHAMMET KARTAL ${ }^{1}$, FANG XIA ${ }^{1, *}$, IDOWU A. ADEGOKE $^{1}$, DAVID RALPH ${ }^{1}$, JITENDRA MATA ${ }^{2}$, ANNA SOKOLOVA ${ }^{2}$

${ }^{1}$ Discipline of Chemistry and Physics, College of Science, Health, Engineering and Education, Murdoch University, Perth, WA 6150, Australia (*correspondence:

f.xia@murdoch.edu.au)

${ }^{2}$ ACNS, Australian Nuclear Science and Technology

Organisation, Lucas Heights, NSW 2234, Australia

Mineral porosity and the related permeability provides pathways for hydrothermal fluids flow in the Earth's crust. Hence, knowledge of porosity creation and evolution is crucial for understanding ore deposition. Much of mineral porosity is created by fluid-mineral reactions, yet the mechanism is not clearly known. We carried out a quantitative study on mineral porosity during mineral replacement of nonporous pentlandite $\left((\mathrm{Fe}, \mathrm{Ni})_{9} \mathrm{~S}_{8}\right)$ by porous violarite $\left((\mathrm{Fe}, \mathrm{Ni})_{2} \mathrm{~S}_{4}\right)$ under laboratory hydrothermal conditions at $125{ }^{\circ} \mathrm{C}$ and $\mathrm{pH} 4$. The reaction progress and crystallite size were determined by Rietveld analyses of synchrotron powder X-ray diffraction and the porosity was characterized by (ultra) small angle neutron scattering (USANS/SANS) and scanning electron microscopy (SEM). USANS/SANS provided total porosity, pore size distribution, and open/closed pore ratio (using contrast matching fluids), while SEM showed pore geometry and spatial distribution.

The results showed that violarite contains a wide size range of pores from nano to micrometres; most pores are open while those below $\sim 10 \mathrm{~nm}$ are mainly closed. The nano pores became more abundant with the advancement of replacement up to $80 \%$ pentlandite was replaced by violarite, then the nano pores started to connect with each other forming nano-/micro-channels, which remained unchanged even after 4 weeks of complete replacement. Violarite crystal size increased during the replacement, probably indicating epitaxial growth processes; but crystal size did not change after complete replacement, suggesting no or extremely slow Ostwald ripening, which is in agreement with natural violarite that often have similar pore texture and crystallite size.

This quantitative examination of reaction-induced porosity has provided insights into the porosity evolution during fluid-mineral interactions. 